\author{
Vladas Vekteris \\ Andrius Styra \\ Vadim Mokšin \\ Irina Grinbergiene \\ Mindaugas Jurevičius \\ Vytautas Turla $\bowtie$ \\ Gyula Mester
}

https://doi.org/10.21278/TOF.42208

ISSN 1333-1124

eISSN 1849-1391

\title{
NUMERICAL SIMULATION OF A PULSATING FLOW GENERATED IN AN EJECTOR
}

\begin{abstract}
Summary
This paper presents a numerical simulation of a pulsating flow generated inside an ejector; the flow is intended to oxidize ferrous iron $\left(\mathrm{Fe}^{2+}\right)$ dissolved in drinking water to ferric iron $\left(\mathrm{Fe}^{3+}\right)$. The pulsating flow ejector can be used in water treatment systems where the water is saturated with oxygen before being treated by filters. It is shown that the pulsating flow is generated due to fluctuations in the pressure, density, and velocity of the flow inside the ejector. It is established that the flow pressure inside the ejector varies from 0.513 to $0.0719 \mathrm{MPa}$, the flow density varies from 4.64 to $0.66 \mathrm{~kg} / \mathrm{m}^{3}$, and the flow velocity varies from 0 to $590 \mathrm{~m} / \mathrm{s}$. Numerical simulation results have shown that an acoustic field is generated inside the ejector during the mixing of air with water, which accelerates the coagulation of iron particles. The obtained sound power level value of $100 \mathrm{~dB}$ shows that the pulsating flow ejector can be used for non-reagent water treatment.
\end{abstract}

Key words: $\quad$ pulsating flow ejector, acoustic field, numerical simulation, sound power

\section{Introduction}

Schemes for pulsating flow generation in ejectors are constantly being improved and research is under way to extend the scope of application of pulsating flows. A question is raised about the use of acoustic vibrations generated by a pulsating flow in the water. However, the method is poorly studied theoretically. Acoustic wave propagation in different media is a very complex phenomenon which is accompanied by different processes, such as cavitation [1], shock waves, microflows, sonochemistry [2, 3], and sonoluminescence [4]. These processes take place at the same time and also interact with each other. Therefore, there are difficulties in describing experimental results. The use of acoustics to accelerate oxidation processes in the water and to precipitate sediments makes it possible to extend the scope of application of this approach $[5,6]$. 
Physical and chemical effects occur in the presence of acoustic field due to elastic vibrations or mechanical reactions. Sonochemical reactions are close to phenomena such as radiolysis, photolysis, and electric discharge [7].

It was proved by scientists that oxidation reactions are significantly accelerated in the presence of sound waves. Other reactions, such as decomposition, polymerization, and depolymerization, are accelerated as well as molecular rearrangements [8-11].

Chemical reactions that occur due to acoustic excitation can be divided into the following types: redox reactions in solutions, cavitation of dissolved gases (formation of bubbles), decomposition reactions of macromolecules that lead to the polymerization effect, and stereoisomerization chain reactions [12].

Acceleration of reactions caused by sound waves is associated with the acoustic cavitation phenomenon. Bubbles are formed from submicroscopic particles of gas and vapour dissolved in the fluid, and then they are aggregated to millimeter-sized particles which pulsate with acoustic frequencies and merge during a positive pressure phase [13].

When sound waves of higher than $10^{-4} \mathrm{~W} / \mathrm{m}^{2}$ intensity are generated in a fluid, microexplosions occur in the continuous medium. The cavities thus created are filled with vapour and dissolved gases; these cavities turn the single phase fluid into a two-phase system. As a rule, the degasification process is accelerated by cavitation in the fluids containing large enough amounts of dissolved gases. In most cases, a sound-induced chemical reaction is accompanied by a particle emission influenced by the nature of substances present in the liquid medium [14].

Any kind of particle collision is effective in quick particle coagulation. Creation of the quick coagulation theory was a rather simple task; it was developed by M. Smoluchowski in 1916.

The following assumptions were made in theoretical studies: the dispersed phase particles have spherical shape, and the particles are monodisperse, i.e. they are the same size. Coagulation rate was determined by four factors: particle attractive force radius, Brownian motion intensity which defines the number of particle collisions per a unit of time, the initial concentration of particles, and the attractive force.

These statements show that at some instant $t_{0}$, the particle repulsive force suddenly disappears; after that point of time, any particle collision causes particle adhesion.

A pulsating flow is caused by flow velocity, pressure, and density fluctuations. In the reduced pressure zone of the liquid, the dissolved air is being released in the form of bubbles. As pressure continues to decrease, the air bubbles aggregate and their volume increases. The vapour bubbles are released from the liquid and then mix with air.

If the pressure drops to the level when the liquid begins to boil, then a zone of vapour bubbles is formed near a local hydraulic obstacle. These bubbles are transferred by flow to the higher pressure zone where they condense. The condensation process is fast and the cavities left by the gas are immediately filled by liquid. The liquid particles move with a high velocity, but when the liquid phase fills the cavities, the velocity suddenly drops to zero. Colliding liquid particles create high pressures. If the condensation area is located near a rigid wall, a high frequency and intensity water hammer acts on the wall surface and causes its erosive wear. Those shocks also cause noise and vibrations of a rigid surface.

Studies show that the cavitation phenomenon in the ejector depends on the difference between the flow pressure before the mixing chamber and that in the mixing chamber. Cavitation also depends on the squared velocity of the flow before the mixing chamber. In most cases, pulsating flows are investigated by numerical simulation. At present, such flows are simulated using the Finite Element Method (FEM). Some software packages utilize the 
Finite Difference Method (FDM) and the Finite Volume Method (FVT) - a method for representing and evaluating partial differential equations in the form of algebraic equations [15]. In the FVT, similarly to the FDM or FEM, values are calculated at discrete places on a meshed geometry. The "Finite volume" refers to the small volume surrounding each node point on a mesh.
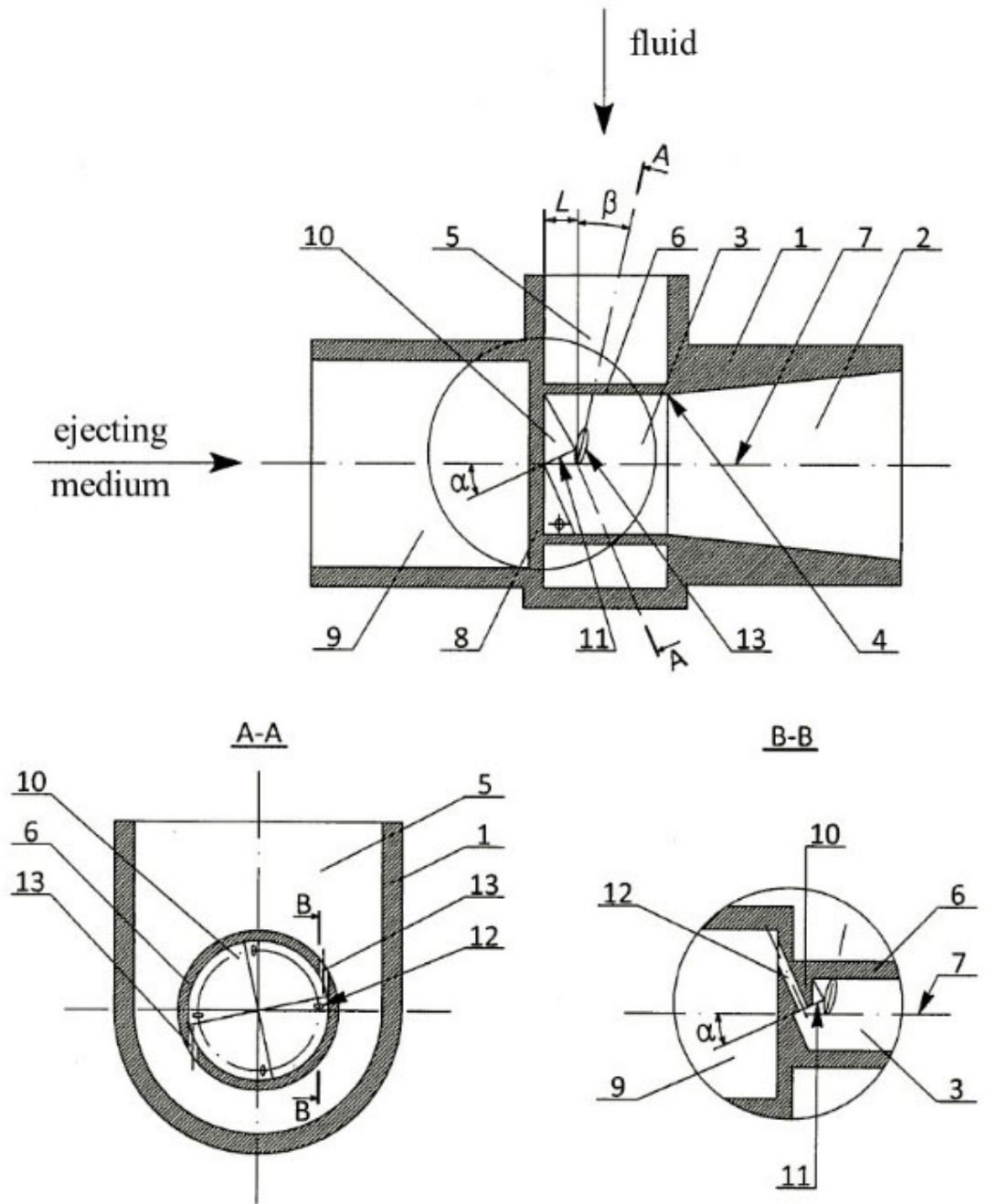

Fig. 1 The pulsating flow ejector [16]: 1 - housing, 2 - diffuser, 3 - mixing chamber, 4 - beginning of conical part, 5 - fluid chamber, 6 - cylindrical wall, 7 - axis, 8 - bottom wall of mixing chamber, 9 - ejecting medium (air) chamber, 10 - pyramid-shaped bulge, 11 - plane of the bulge, 12, 13 - holes

\section{Test ejector structure}

A drawing of the pulsating flow ejector [16] is shown in Fig. 1. The ejector consists of a housing (1), which has a conical diffuser (2) at the end. The cylindrical mixing chamber (3) is connected with the diffuser (2). The mixing chamber (3) is separated from the fluid chamber (5) by a wall (6). The bottom wall (8) separates the mixing chamber (3) from the ejecting medium (air) chamber (9), which is formed at the opposite end of the housing (1). Oblique triangular pyramid-shaped bulges (10) are distributed on the bottom wall (8) of the mixing chamber (3). Their narrowest planes (11) make angles $\alpha$ with the axis (7) of the mixing chamber (3). Holes (12) connecting the mixing chamber (3) with the ejecting medium chamber (9) are drilled in the surfaces (11) of the bulges (10). Tangential holes (13) connecting the mixing chamber (3) with the fluid chamber (5) are drilled in the cylindrical wall (6). Their axes make angles $\beta$ with the bottom wall (8) of the mixing chamber (3). The 
fluid under pressure is supplied to the fluid chamber (5) (Fig. 1); then, it enters the mixing chamber (3) tangentially through the holes (13) to generate a swirling flow. Due to the inclination of axes of the holes (13), the rotating flow is directed towards the bottom wall (8)of the mixing chamber (3). When the flow reaches the bottom wall (8), additional turbulence is generated by bulges (10). As the bulge height is variable and decreases towards the axis of rotation of the flow (7) (or the axis of the cylindrical mixing chamber (3)), the turbulence intensity remains constant along the edge of the bulge (10). The swirling flow, by passing the bulge (10), creates the negative pressure over the hole (12), which connects the mixing chamber (3) with the ejecting medium (air) chamber (9). Under the action of negative pressure, the ejecting medium begins to enter the mixing chamber (3) through the holes (12) and mixes with the fluid due to the generated turbulence. As the mixture density is changed, the dynamic pressure of the flow is changed as well as the ratio of dynamic and static pressures. When the static pressure increases, the swirling flow moves towards the diffuser (2), thus preventing the access of the fluid to the mixing chamber (3) through the holes (13). The static pressure drops as a result of this movement; the dynamic pressure increases proportionally and the fluid gains access to the mixing chamber (3) again.

\section{Numerical procedure}

The SolidWorks ${ }^{\circledR}$ Flow Simulation 2011 SP2.0 software was used for numerical simulation of pulsating flow inside the ejector. To predict a turbulent flow, Flow Simulation solves the Favre-averaged Navier-Stokes equations, in which the flow turbulence timeaveraged effects on the flow parameters are considered. On the other hand, other phenomena, i.e. large-scale, time-dependent phenomena, are taken into account directly. Through this procedure, extra terms known as the Reynolds stresses appear in the equations for which additional information must be provided. To close this system of equations, transport equations for the turbulent kinetic energy and its dissipation rate are employed (the so-called $k-\varepsilon$ model) $[17,18]$.

Flow Simulation uses the same equations to describe both laminar and turbulent flows. Moreover, transitions from one case to another and back are possible [17].

The conservation laws for mass, angular momentum, and energy in the Cartesian coordinate system rotating at an angular velocity about an axis passing through the coordinate system origin can be written in the conservation form as follows [17, 19]:

$$
\begin{aligned}
& \frac{\partial \rho}{\partial t}+\frac{\partial}{\partial x_{i}}\left(\rho u_{i}\right)=0, \\
& \frac{\partial \rho u_{i}}{\partial t}+\frac{\partial}{\partial x_{j}}\left(\rho u_{i} u_{j}\right)+\frac{\partial p}{\partial x_{i}}=\frac{\partial}{\partial x_{j}}\left(\tau_{i j}+\tau_{i j}^{R}\right)+S_{i}, \quad i=1,2,3, \\
& \frac{\partial \rho H}{\partial t}+\frac{\partial \rho u_{i} H}{\partial x_{i}}=\frac{\partial}{\partial x_{i}}\left(u_{j}\left(\tau_{i j}+\tau_{i j}^{R}\right)+q_{i}\right)+\frac{\partial p}{\partial t}-\tau_{i j}^{R} \frac{\partial u_{i}}{\partial x_{j}}+\rho \varepsilon+S_{i} u_{i}+Q_{H}, \\
& H=h+\frac{u^{2}}{2} .
\end{aligned}
$$

where $u$ is the fluid velocity, $p$ is the pressure, $\rho$ is the fluid density, $S_{i}$ is the mass-distributed external force, $h$ is the thermal enthalpy, $Q_{H}$ is the heat source or sink per unit volume, $\tau_{i j}$ is the viscous shear stress tensor, $\tau_{i j}^{R}$ is the Reynolds-stress tensor, $q_{i}$ is the diffusive heat flux, 
and $\varepsilon$ is the turbulent dissipation. The subscripts are used to denote the summation over the three coordinate directions.

It is assumed that the water and air mixture is a Newtonian fluid. For Newtonian fluids $\tau_{i j}$ can be defined as:

$$
\tau_{i j}=\mu\left(\frac{\partial u_{i}}{\partial x_{j}}+\frac{\partial u_{j}}{\partial x_{i}}-\frac{2}{3} \delta_{i j} \frac{\partial u_{k}}{\partial x_{k}}\right)
$$

where $\delta_{i j}$ is the Kronecker delta function and $\mu$ is the dynamic viscosity. form:

Following the Boussinesq assumption, the Reynolds-stress tensor has the following

$$
\tau_{i j}^{R}=\mu_{t}\left(\frac{\partial u_{i}}{\partial x_{j}}+\frac{\partial u_{j}}{\partial x_{i}}-\frac{2}{3} \delta_{i j} \frac{\partial u_{k}}{\partial x_{k}}\right)-\frac{2}{3} \rho k \delta_{i j} .
$$

where $\mu_{t}$ is the turbulent eddy viscosity coefficient and $k$ is the turbulent kinetic energy $\left(\mu_{t}\right.$ and $k$ are zero for laminar flows).

In the frame of the $k$ - $\varepsilon$ turbulence model [17],

$$
\mu_{t}=f_{\mu} \frac{C_{\mu} \rho k^{2}}{\varepsilon}
$$

where $C_{\mu}$ is the constant and $f_{\mu}$ is the turbulent viscosity factor which is defined by the following expression:

$$
f_{\mu}=\left[1-e^{-0.025 R_{y}}\right]^{2}\left(1+\frac{20.5}{R_{t}}\right)
$$

where $y$ is the distance to the wall, $R_{t}=\frac{\rho k^{2}}{\mu \varepsilon}, R_{y}=\frac{\rho \sqrt{k} y_{w}}{\mu}$.

Two additional transport equations are used to describe the turbulent kinetic energy and dissipation [17]:

$$
\begin{aligned}
& \frac{\partial \rho k}{\partial t}+\frac{\partial}{\partial x_{i}}\left(\rho u_{i} k\right)=\frac{\partial}{\partial x_{i}}\left(\left(\mu+\frac{\mu_{t}}{\sigma_{k}}\right) \frac{\partial k}{\partial x_{i}}\right)+S_{k}, \\
& \frac{\partial \rho \varepsilon}{\partial t}+\frac{\partial}{\partial x_{i}}\left(\rho u_{i} \varepsilon\right)=\frac{\partial}{\partial x_{i}}\left(\left(\mu+\frac{\mu_{t}}{\sigma_{\varepsilon}}\right) \frac{\partial \varepsilon}{\partial x_{i}}\right)+S_{\varepsilon} .
\end{aligned}
$$

where $\sigma_{k}, \sigma_{\varepsilon}$ are the constants, $S_{k}$ and $S_{\varepsilon}$ are the source terms that are defined as follows:

$$
\begin{aligned}
& S_{k}=\tau_{i j}^{R} \frac{\partial u_{i}}{\partial x_{j}}-\rho \varepsilon+\mu_{t} P_{B}, \\
& S_{\varepsilon}=C_{\varepsilon_{1}} \frac{\varepsilon}{k}\left(f_{1} \tau_{i j}^{R} \frac{\partial u_{i}}{\partial x_{j}}+\mu_{t} C_{B} P_{B}\right)-C_{\varepsilon_{2}} f_{2} \frac{\rho \varepsilon^{2}}{k},
\end{aligned}
$$


where $f_{1}=1+\left(\frac{0.05}{f_{\mu}}\right)^{3}, f_{2}=1-e^{-R_{T}^{2}}, C_{\varepsilon_{1}}, C_{\varepsilon_{2}}, C_{B}$ are the constants, $P_{B}$ represents the turbulence generation due to buoyancy (buoyant force) and can be written as follows:

$$
P_{B}=-\frac{g_{i}}{0.9} \frac{1}{\rho} \frac{\partial \rho}{\partial x_{i}}
$$

where $g_{i}$ is the component of gravitational acceleration in the direction $x_{i}$.

The constant $C_{B}$ is defined as $C_{B}=1$ when $P_{B}>0$, otherwise $C_{B}=0$. The constants $C_{\mu}, C_{\varepsilon_{1}}, C_{\varepsilon_{2}}, \sigma_{k}, \sigma_{\varepsilon}$ are defined empirically. In Flow Simulation, the following typical values are used [17]: $C_{\mu}=0.09, C_{\varepsilon_{1}}=1.44, C_{\varepsilon_{2}}=1.92, \sigma_{k}=1, \sigma_{\varepsilon}=1.3$.

If the Lewis number $L e=1$, the diffusive heat flux is defined as:

$$
q_{i}=\left(\frac{\mu}{\operatorname{Pr}}+\frac{\mu_{t}}{\sigma_{c}}\right) \frac{\partial h}{\partial x_{i}}, \quad i=1,2,3,
$$

where $P r$ is the Prandtl number, $\sigma_{c}$ is the constant $\left(\sigma_{c}=0.9\right)$.

Flow Simulation solves the governing equations using the finite volume (FV) method on a spatially rectangular computational mesh designed in the Cartesian coordinate system with the planes orthogonal to its axes and refined locally at the solid/fluid interface [17].

The cell-centred FV method is used to obtain conservative approximations of the governing equations on the locally refined rectangular mesh. The governing equations are integrated over a control volume, which is a grid cell, and then approximated using the cellcentred values of the basic variables $[17,19]$.

The second-order upwind approximations of fluxes are based on the implicitly treated modified Leonard QUICK Approximations [20] and the Total Variation Diminishing (TVD) method [21].
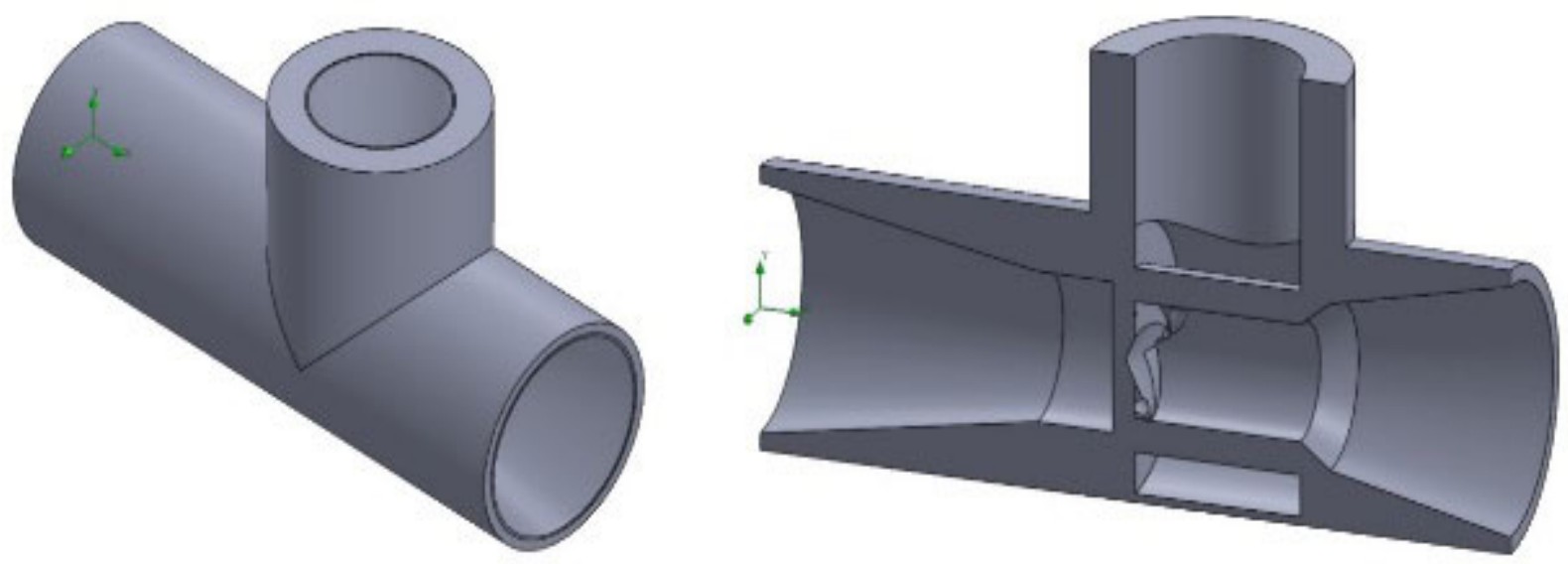

Fig. 2 3D model of the pulsating flow ejector 


\section{Numerical simulation results}

The 3D model of the ejector is presented in Fig. 2. Initial and boundary conditions used for simulation are summarized in Table 1.

Other simulation conditions were the following: initial mesh level -8 (maximum allowable), result resolution level - 8 (maximum allowable).

Table 1 Initial and boundary conditions

\begin{tabular}{|c|c|}
\hline \multicolumn{2}{|c|}{ Initial Conditions } \\
\hline Thermodynamic parameters & $\begin{array}{l}\text { Static Pressure: } 101325.00 \mathrm{~Pa} \\
\text { Temperature: } 293.20 \mathrm{~K}\end{array}$ \\
\hline \multicolumn{2}{|c|}{ Boundary Conditions of Inlet Mass Flow 1 (air) } \\
\hline Type & Inlet Mass Flow \\
\hline Coordinate system & Face Coordinate System \\
\hline Reference axis & $X$ \\
\hline Flow parameters & $\begin{array}{l}\text { Flow vectors direction: Normal to face } \\
\text { Mass flow rate: } 0.0060 \mathrm{~kg} / \mathrm{s} \\
\text { Fully developed flow: No } \\
\text { Inlet profile: } 0\end{array}$ \\
\hline Thermodynamic parameters & $\begin{array}{l}\text { Approximate pressure: } 101325.00 \mathrm{~Pa} \\
\text { Temperature: } 293.20 \mathrm{~K}\end{array}$ \\
\hline Concentrations & $\begin{array}{l}\text { Substance fraction by mass: } \\
\text { Air } 1.0000 \\
\mathrm{H}_{2} \mathrm{O} 0\end{array}$ \\
\hline Boundary layer parameters & Boundary layer type: Turbulent \\
\hline \multicolumn{2}{|c|}{ Boundary Conditions of Inlet Mass Flow 2 (water) } \\
\hline Type & Inlet Mass Flow \\
\hline Coordinate system & Face Coordinate System \\
\hline Reference axis & $X$ \\
\hline Flow parameters & $\begin{array}{l}\text { Flow vectors direction: Normal to face } \\
\text { Mass flow rate: } 0.0040 \mathrm{~kg} / \mathrm{s} \\
\text { Fully developed flow: No } \\
\text { Inlet profile: } 0\end{array}$ \\
\hline Thermodynamic parameters & $\begin{array}{l}\text { Approximate pressure: } 501300.00 \mathrm{~Pa} \\
\text { Temperature: } 293.20 \mathrm{~K}\end{array}$ \\
\hline Concentrations & $\begin{array}{l}\text { Substance fraction by mass: } \\
\text { Air } 0 \\
\mathrm{H}_{2} \mathrm{O} 1.0000\end{array}$ \\
\hline Boundary layer parameters & Boundary layer type: Turbulent \\
\hline \multicolumn{2}{|c|}{ Environment Pressure 1} \\
\hline Type & Environment Pressure \\
\hline Coordinate system & Face Coordinate System \\
\hline Reference axis & $X$ \\
\hline Thermodynamic parameters & $\begin{array}{l}\text { Environment pressure: } 101325.00 \mathrm{~Pa} \\
\text { Temperature: } 293.20 \mathrm{~K}\end{array}$ \\
\hline Concentrations & $\begin{array}{l}\text { Substance fraction by mass: } \\
\text { Air } 0.5000 \\
\mathrm{H}_{2} \mathrm{O} 0.5000\end{array}$ \\
\hline Boundary layer parameters & Boundary layer type: Turbulent \\
\hline \multicolumn{2}{|c|}{ Parameters of the walls } \\
\hline Roughness & 0 \\
\hline Type & Adiabatic (heat-insulated) \\
\hline
\end{tabular}


V. Vekteris, A. Styra, V. Moksin, I. Grinbergiene, M. Jurevicius, V. Turla, G. Mester
Numerical Simulation of a Pulsating Flow Generated in an Ejector

Numerical simulation results are presented in Table 2 and graphically shown in Figs. 3-5. Parameter values of the whole flow model were calculated, rather than of specific sections or points. Minimum and maximum flow parameter values are presented in Table 2 .

It can be seen from Table 2 that minimum and maximum flow pressure, temperature, density, and velocity values obtained from the simulation differ significantly. As one can see from Fig. 3, the flow pressure varies from $0.513 \mathrm{MPa}$ (at the beginning of mixing the air with water) to $0.0719 \mathrm{MPa}$ at the ejector outlet. The flow density (Fig. 4) varies from $4.64 \mathrm{~kg} / \mathrm{m}^{3}$ to $0.66 \mathrm{~kg} / \mathrm{m}^{3}$ (at the outlet). The flow velocity at the outlet reaches $130-150 \mathrm{~m} / \mathrm{s}$ (Fig. 5).

Table 2 The minimum and maximum values of data

\begin{tabular}{|l|l|c|}
\hline Name & Minimum value & Maximum value \\
\hline Density $\left(\right.$ Fluid) $\left[\mathrm{kg} / \mathrm{m}^{3}\right]$ & 0.66 & 4.64 \\
\hline Mass Fraction of Air & $-1.9700 \mathrm{e}-008$ & 1.0000 \\
\hline Mass Fraction of $\mathrm{H}_{2} \mathrm{O}$ & $-1.8374 \mathrm{e}-005$ & 1.0000 \\
\hline Pressure $[\mathrm{Pa}]$ & 71853.39 & 512782.27 \\
\hline Temperature $[\mathrm{K}]$ & 218.50 & 304.58 \\
\hline Velocity $[\mathrm{m} / \mathrm{s}]$ & 0 & 590.045 \\
\hline Velocity $(\mathrm{X})[\mathrm{m} / \mathrm{s}]$ & -198.909 & 295.747 \\
\hline Velocity $(\mathrm{Y})[\mathrm{m} / \mathrm{s}]$ & -572.448 & 578.226 \\
\hline Velocity $(\mathrm{Z})[\mathrm{m} / \mathrm{s}]$ & -337.202 & 323.819 \\
\hline Volume Fraction of Air & $-1.2255 \mathrm{e}-008$ & 1.0000 \\
\hline Volume Fraction of $\mathrm{H}_{2} \mathrm{O}$ & $-2.9536 \mathrm{e}-005$ & 1.0000 \\
\hline Mach Number & 0 & 1.65 \\
\hline Vorticity $[1 / \mathrm{s}]$ & 0.19 & 1176894.23 \\
\hline Relative Pressure $[\mathrm{Pa}]$ & -29471.61 & 411457.27 \\
\hline Shear Stress $[\mathrm{Pa}]$ & 0 & 8831.77 \\
\hline Bottleneck Number & $1.7041038 \mathrm{e}-019$ & 1.0000000 \\
\hline Heat Transfer Coefficient $\left[\mathrm{W} / \mathrm{m}^{2} / \mathrm{K}\right]$ & 0 & 0 \\
\hline ShortCut Number & $5.4080029 \mathrm{e}-021$ & 1.0000000 \\
\hline Surface Heat Flux $\left[\mathrm{W} / \mathrm{m}^{2}\right]$ & 0 & 0 \\
\hline Surface Heat Flux $(\mathrm{Convective})\left[\mathrm{W} / \mathrm{m}^{2}\right]$ & $-7.166 \mathrm{e}+007$ & $2.182 \mathrm{e}+007$ \\
\hline & & \\
\hline
\end{tabular}

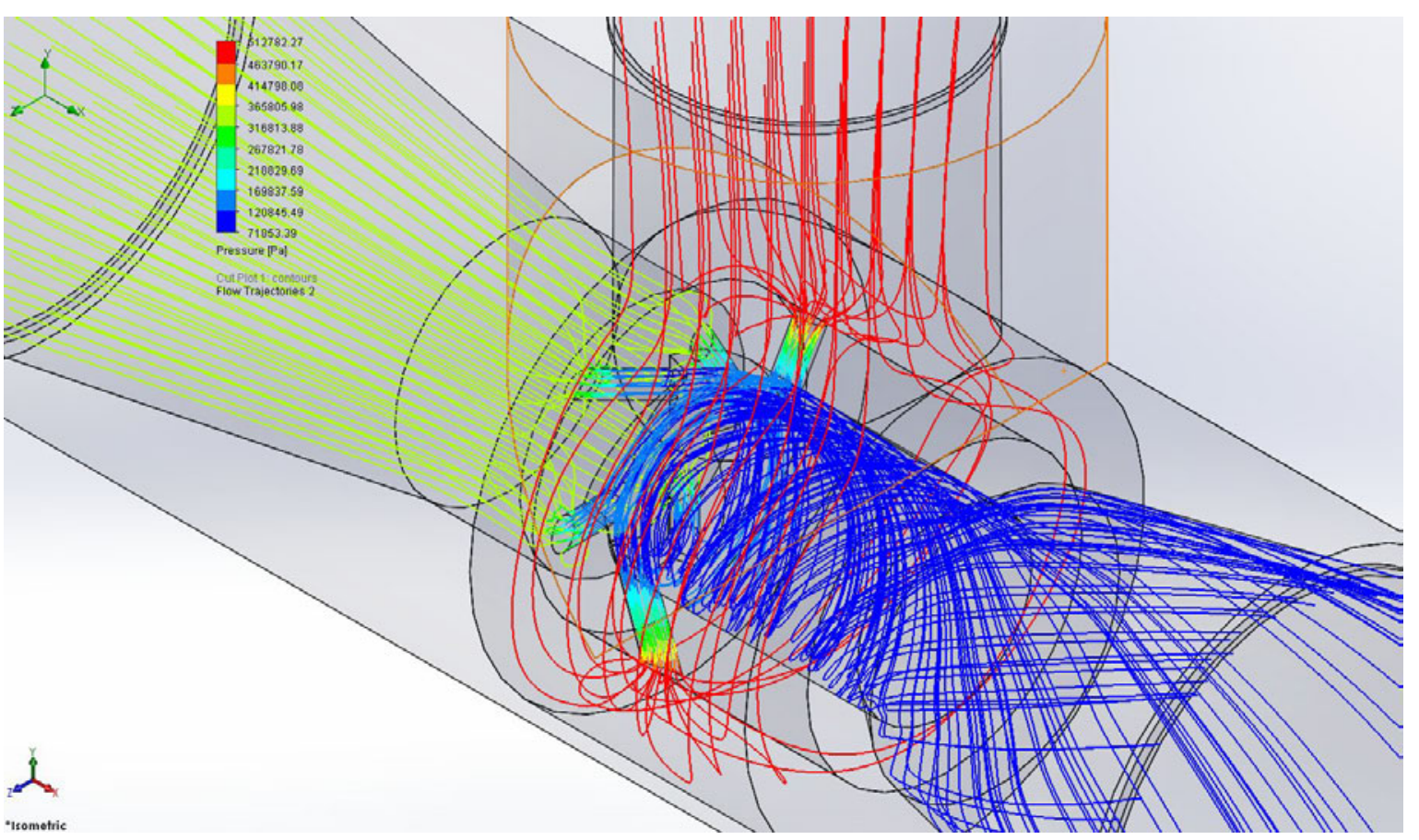

Fig. 3 Flow pressure distribution map 


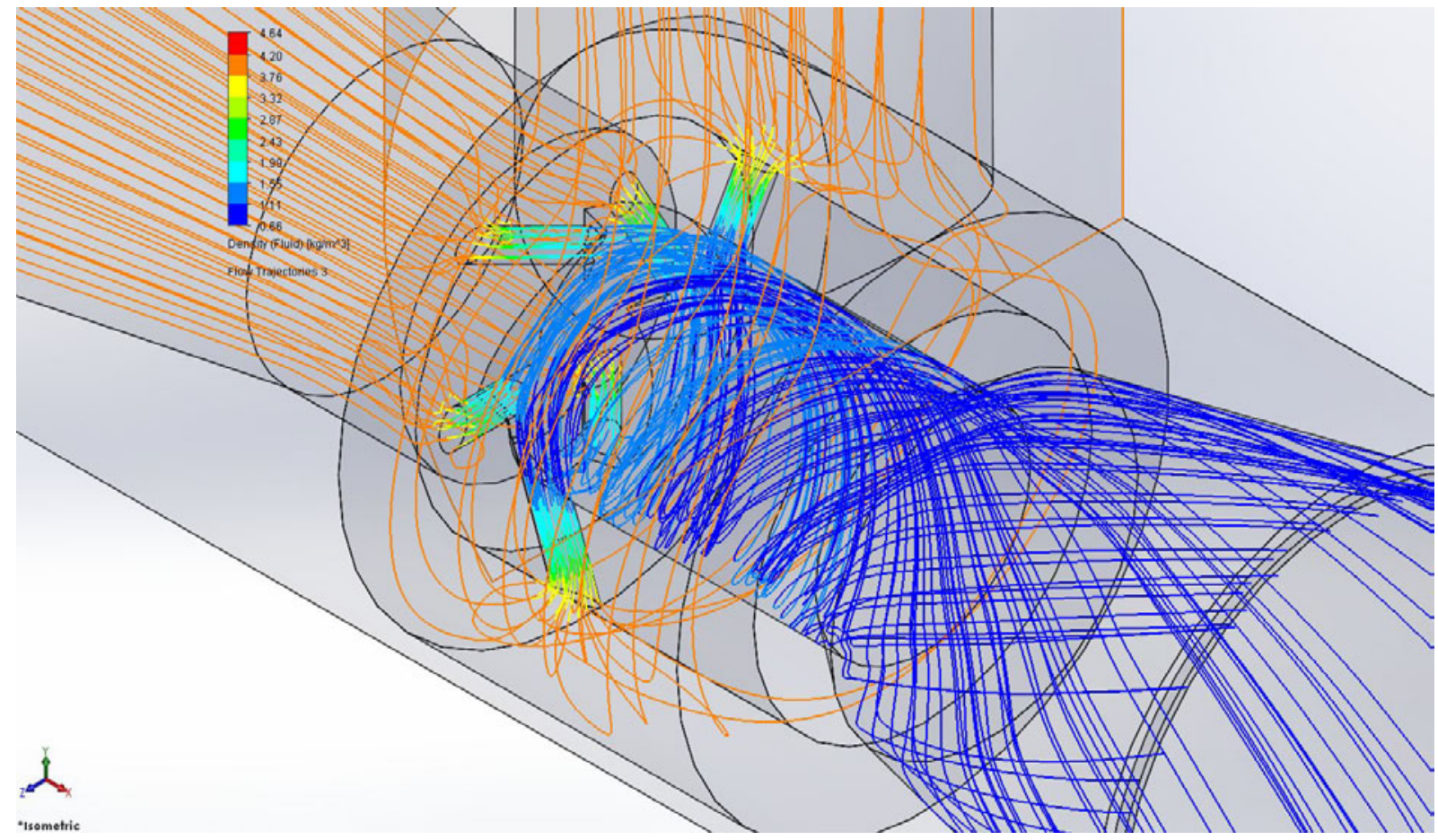

Fig. 4 Flow density distribution map

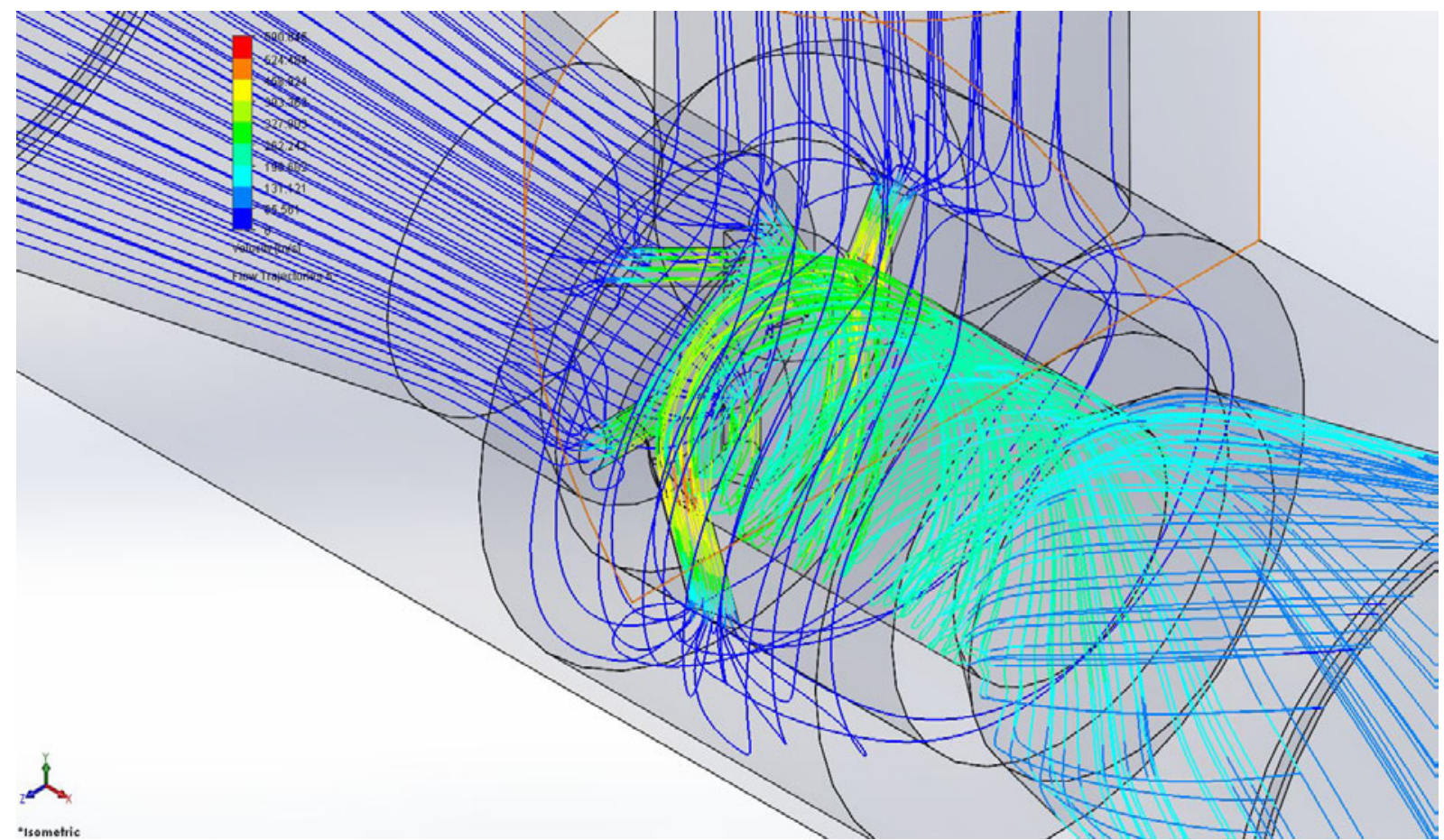

Fig. 5 Flow velocity distribution map

The examination of Lighthill's equation [22] based on the dimension theory allows us to calculate the power of flow-induced sound:

$$
L_{w}=10 \lg \left(k_{0} \frac{\rho_{0}^{2} v_{0}^{8} d^{2}}{W_{0} \rho_{\infty} c_{\infty}^{5}}\right),
$$


where $L_{w}$ is the sound power level, $v_{0}$ is the outflow velocity, $\rho_{0}$ is the density of the flow exiting the nozzle, $\rho_{\infty}$ is the density of the surrounding medium, $k_{0}$ is the coefficient whose value varies from $3 \cdot 10^{-5}$ to $(1.5-2.5) \cdot 10^{-5}, d$ is the diameter of the outlet nozzle, $c_{\infty}$ is the speed of sound in water, $W_{0}=10^{-12} \mathrm{~W}$.

It is known that to ensure acoustic coagulation, the sound intensity should not be less than $10^{-4} \mathrm{~W} / \mathrm{m}^{2}$. After inserting numerical simulation results into Eq. (15), we obtain the sound power level of $100.19 \mathrm{~dB}$, which represents a sound intensity of $10^{-2} \mathrm{~W} / \mathrm{m}^{2}$; that value is above the value required for the acoustic coagulation.

\section{Conclusions}

Numerical studies have shown that the maximum fluctuations of flow pressure and density take place in the mixing chamber of the ejector during the mixing of the air with water. This results in the $0.0719 \mathrm{MPa}$ pressure of the outlet flow and a flow density of 0.66 $\mathrm{kg} / \mathrm{m}^{3}$. Pressure and density fluctuations generate the acoustic field which causes the iron particles dissolved in the water to interact with each other, adhere to each other, and aggregate; finally, they are deposited on the bottom of the tank under the action of gravitational forces.

Numerical simulation results demonstrated the pulsating behaviour of the flow in the ejector expressed as changes in the flow density, the pressure, and the velocity; in addition, they also demonstrated the acoustic effectiveness of the ejector. The theoretically obtained sound power level value of $100.19 \mathrm{~dB}$, which represents a sound intensity of $10^{-2} \mathrm{~W} / \mathrm{m}^{2}$, is above the value required for the acoustic coagulation.

\section{REFERENCES}

[1] A. Jafarian, A. Pishevar: Numerical simulation of steady supercavitating flows, J Appl Fluid Mech, 9, 6, 2016, 2981-2992.

[2] L. Stricker: Acoustic Cavitation and Sonochemistry. Ph. D. thesis, University of Twente, Enschede, 2013.

[3] K.S. Suslick: Mechanochemistry and sonochemistry: concluding remarks, Faraday Discuss, 170, 2014, 411-422. https://doi.org/10.1039/C4FD00148F

[4] K.S. Suslick, Y. Didenko, M.M. Fang, T. Hyeon, K.J. Kolbeck, W.B. McNamara, M.M. Mdleleni and M. Wong: Acoustic cavitation and its chemical consequences, Phil Trans R Soc Lond A, 357, 1751, 1999, 335-353.

[5] I.N. Kozachiuk: Use of the Ultrasound to Intensify the Sedimentation of Particles Suspended in the Sewage. Ph. D. thesis, Moscow State University of Civil Engineering, Moscow, 2009 (In Russian).

[6] A.V. Vikulin: Physics of the Earth and Geodynamics, Kamchatka State University, PetropavlovskKamchatsky, 2009 (In Russian).

[7] P.Y. Butyagin: Kinetics and nature of Mechanochemical reactions, Russ Chem Rev, 40, 11, 1971, 901915.

[8] R. Anbarasan, J. Jayaseharan, M. Sudha and A. Gopalan: Sonochemical polymerization of acrylic acid and acrylamide in the presence of a new redox system - a comparative study, J Appl Polym Sci, 89, 13, 2003, 3685-3692.

[9] A.Y. Baranchikov, V.K. Ivanov and Y.D. Tretyakov: Sonochemical synthesis of inorganic materials, Russ Chem Rev, 76, 2, 2007, 133-151.

[10] L. Bergmann: Der Ultraschall und Seine Anwendung in Wissenschaft und Technik, S. Hirzel Verlag, Stuttgart, 1954.

[11] T.X.T. Luu, H.T. Le, T.N. Le and F. Duus: Microwave- and ultrasound-accelerated green permanganate oxidation of thioethers, Organic Chem Curr Res, 4, 1, 2015, 1-5.

[12] I.G. Polockij: Chemical action of cavitation, Zhurnal Obshchei Khimii, 17, 6, 1947, 1048-1054 (In Russian).

[13] I.E. Elpiner: Biophysics of Ultrasound, Nauka, Moscow, 1973 (In Russian).

[14] L.D. Rozenberg: Sources of High-Intensity Ultrasound, Plenum Press, New York, 1969. 
[15] R.J. LeVeque: Finite Volume Methods for Hyperbolic Problems, Cambridge University Press, Cambridge, 2002. https://doi.org/10.1017/CBO9780511791253

[16] V. Vekteris, A. Styra, V. Striska and A. Kilikevicius: Pulsating Flow Ejector. LT Patent LT6011B, The State Patent Bureau of the Republic of Lithuania, Vilnius, 2015 (In Lithuanian).

[17] SolidWorks Flow Simulation 2009 Technical Reference, Dassault Systemes SolidWorks Corporation, Waltham, 2009.

[18] Debnath, P., Pandey, K. M. (2017). Numerical Investigation of Detonation Combustion Wave in Pulse Detonation Combustor with Ejector. Journal of Applied Fluid Mechanics, 10(2), 725-733. https://doi.org/10.18869/acadpub.jafm.73.239.27266

[19] T. Islam and S.M. Rakibul Hassan: Experimental and numerical investigation of flow over a cylinder at Reynolds number $10^{5}$, Journal of Modern Science and Technology, 1, 1, 2013, 52-60.

[20] R.L. Panton: Incompressible Flow, John Wiley \& Sons, New York, 1996.

[21] F.M. White: Fluid Mechanics, McGraw-Hill, New York, 1994.

[22] M.J. Lighthill: On sound generated aerodynamically: I. Turbulence as a source of sound, $\operatorname{Proc} R$ Soc A, 222, 1954, 1-32. https://doi.org/10.1098/rspa.1954.0049

Submitted: $\quad 05.10 .2017$

Accepted: $\quad 31.01 .2018$ prof. Vladas Vekteris, Dr. Habil.

lect. Andrius Styra

prof. Vadim Mokšin, Ph. D.

lect. Irina Grinbergienè

prof. Mindaugas Jurevičius, Ph. D.

Vilnius Gediminas Technical University

Department of Mechanical and Material

Engineering

J. Basanavičiaus str. 28

03224 Vilnius, Lithuania

prof. Vytautas Turla ${ }^{*}$ Ph. D.

Vilnius Gediminas Technical University

Department of Mechatronic, Robotics and

Digital Manufacturing

J. Basanavičiaus str. 28

03224 Vilnius, Lithuania

prof. Gyula Mester, Ph. D.

Óbuda University,

Doctoral School of Safety and Security

Sciences

Bécsi út 96b,

H-1034 Budapest, Hungary

*corresponding author

e-mail:vytautas.turla@vgtu.lt 